\title{
Experimental Research on Fatigue Performance of Modified Asphalt Mixture Containing Aged Plastic Particles
}

\author{
Ibrahima SAW ${ }^{1}$, Ibrahima Khalil CIOIE ${ }^{2}$ \\ ${ }^{1}$ Doctoral School of the University of Thies (ed2ds), Senegal \& Comapagnie Sahélienned' Entreprises, Dakar, Senegal \\ ${ }^{2}$ Laboratoire de Matériaux, Mécanique et Hydraulique (LMMH), Ecole Polytechnique de thiès, Thiès, Sénégal
}

\begin{abstract}
Recently warm mix asphalt (WMA) technologies have been introduced to rubberized asphalt mixtures to decrease the required construction temperatures and alleviate hazardous gas emissions. Molten plastic asphalt pavements combining with WMA have the potential to improve long - term pavement performance. This study aims to investigate the fatigue performance of modified bitumen with molten plastic (MP) containing warm - mix additives using different characterization methods. The effects of molten plastic modifier (MP) content (5\%, 10\%, 15\%, and $20 \%$ by weight of base bitumen) and warm - mix additives on the binder fatigue performance were investigated. Various laboratory tests, including frequency sweep tests, time sweep (TS) tests and linear amplitude sweep (LAS) tests, were conducted on the long - term aged binders to obtain indicators of fatigue performance. Results show that there is a good correlation between the measured fatigue life determined by TS tests using the dissipated energy concept and the predicted fatigue life determined by LAS tests using the simplified viscoelastic continuum damage (S - VECD) theory. However, the traditional Superpave fatigue parameter and the $G-R$ parameter cannot characterize accurate enough the fatigue performance of modified binders. Modified binders exhibit superior fatigue performance compared to the neat bitumen. The effects of warm - mix additives on the fatigue performance are different for neat bitumen compared to modify binder. Based on the findings in this study, rubberized asphalt mixture combining with WMA additives is expected to have a promising long - term fatigue performance.
\end{abstract}

Keywords: Molten plastic, Modify bitumen, fatigue, performance

\section{Introduction}

Due to the increased awareness of environmental issues and potential economic benefits, engineers are trying to develop a more sustainable framework for eliminating plastic waste. From the point of view of materials science, plastic is made of elastomer, polyethylene terephthalate... In civil engineering, the modification of bitumen by adding plastic powder has been successfully applied in the construction industry. asphalt due to economic benefits and environmental concerns.

\section{1) Bitumen modified by adding plastic granules}

1.1. Combination of plastic powder modified bitumen and hot - mix asphalt technology

Research has shown that modification with plastic granules improves the rheological properties of binders [4, 5]. However, the use of modified bitumen by adding plastic raises some concerns due to its high viscosity, such as poor pumpability, poor mixability, and workability, as well as high thermal energy consumption during the production phase. in the asphalt plant. Hot Asphalt Technologies (WMA) can help lower hot asphalt construction temperatures (HMA) by reducing viscosity, improving lubricity, or both [7-9]. Adding the plastic granulate to the bitumen is a promising and sustainable technology with many advantages, such as energy conservation, environmental protection, optimization of performance, and extension of durability [10-12].
Fatigue cracking of asphalt pavements caused by repeated traffic loads at intermediate temperatures is a major problem during the commissioning period, which is an important factor in determining the durability of asphalt concrete pavements. The fatigue performance of asphalt mixes is strongly linked to the viscoelastic binder which determines the rheological, cohesive, and adhesive behaviors of asphalt mixes at different material scales [13, 14]. Binders with good fatigue performance are beneficial in improving the fatigue resistance of asphalt mixtures. Therefore, an accurate and efficient characterization of the fatigue performance of modified bitumen by adding plastic granules with hot additives is of great importance to optimize the design of the mixture and to prolong the life of the pavements.

1.2. Characterization of the fatigue of binders using a dynamic shear rheometer

The efficient and accurate characterization of the fatigue performance of bituminous binders is important for the classification of binders and the classification and prediction of performance [15]. The current specifications for the performance classification of asphalt mixes use the so called fatigue parameter $(\mathrm{G} * \sin \mathrm{d})$ to assess the resistance of the binder to fatigue cracking. It is based on the linear viscoelastic properties (VEL) of the aged RTFOT and PAV binder obtained from a dynamic shear rheometer (RCD) at a frequency of $10 \mathrm{rad} / \mathrm{s}$ [16]. A major drawback of this fatigue parameter is that it cannot really account for actual damage as it is determined in the VEL range of the binder where the nonlinear response is not captured [17]. Previous studies have shown that the $\mathrm{G} * \sin \mathrm{d}$ parameter of binders has a weak correlation with the fatigue performance of the asphalt mix. This is more evident for modified binders [18] 
Recently, another rheological parameter $\mathrm{G} *(\cos \delta) 2 / \sin \delta$ also based on the VEL properties of RCD tests has been proposed [19]. This parameter is called the Glover - Rowe $(\mathrm{G}-\mathrm{R})$ parameter, which can be calculated from the results of frequency sweep tests at $15 \mathrm{LC}$ and $0.005 \mathrm{rad} / \mathrm{s}$. The G $\mathrm{R}$ parameter showed a very strong correlation with the ductility of the binder and can be used as an index to quantify the resistance to cracking of the binder. A higher value of this parameter indicates an increased brittleness or a decrease in the ductility of the binders [20]. Although the $G$ - $\mathrm{R}$ parameter correlates well with the resistance to cracking of pavements with unmodified bitumen mixtures, it is still necessary to investigate whether it is still valid for polymer modified binders. In addition to the uncertainty of the fatigue parameters and the GR parameter to characterize the fatigue strength of modified binders, these two parameters have the following limitations: (1) both parameters are based on a single point measurement at a temperature and a frequency. Therefore, they do not provide any insight into the evolution of fatigue damage and the effects of temperature and loading rates. (2) Both parameters only consider the hardware response in the VEL range. Binders can experience much higher levels of deformation in the actual pavement structure. In summary, these two parameters cannot explain the effect of the magnitude of the traffic load and relate fatigue life to strain/stress levels.

To overcome the limitations of the above parameters, different test approaches and analytical methods have been introduced to improve the fatigue characterization of binders. One of the introduced tests based on the same RCD measurement system to study the fatigue properties of the binder is the temporal sweep test (TS). A repeated stress controlled or stress - controlled cyclic load is applied to the binder specimen in the BT test at a fixed frequency and temperature [21]. The number of load cycles to failure at prescribed stress or strain amplitude is generally used as an index to quantify the fatigue performance of the binder. Different definitions of fatigue failure, e. g., stiffness reduction or physical failure, phase angle peak, SN peak (stiffness multiplied by load cycles), the concept of dissipated energy, etc., are proposed for fatigue analysis [22, 23]. In particular, the dissipated energy (DE) parameters [24] have been widely used to identify the point of fatigue failure to determine the fatigue life of the binder. It has been reported that the results of TS (Time Sweep) tests can be effectively linked to fatigue field performance [25]. The obvious shortcomings of TS include the uncertainty of the instability flow which interferes with fatigue analysis and long test duration. Under these conditions, the Linear Amplitude Sweep (LAS) test was developed to accelerate the binder fatigue process. This test procedure also involves cyclic loading on a binder specimen at a constant temperature and frequency with the RCD, but with increasing amplitude of strain in stages. The Simplified Viscoelastic Continuum Damage Theory (S - VECD) was used for the analysis of LAS test results and the prediction of the fatigue life of the binder at any strain amplitude of interest. As with the TS test, the fatigue failure point must be clearly defined to allow the prediction of fatigue life. The fatigue failure thresholds proposed in the LAS test include a $35 \%$ reduction in so - called material integrity (as represented by $\mathrm{G} * \sin \square$ ), peak phase angle, peak shear stress, and peak CN (material integrity time loading cycles) [26]. More recently, a definition and a failure criterion based on pseudo - strain energy (PSE) have been developed and implemented in S - VECD modeling to predict the fatigue life of the binder [27]. The binder fatigue strength predicted from the LAS test results was found to show a promising correlation with the crack length measured in actual asphalt pavements from the Long - Term Pavement Preservation Program (LTPP) [28]. Since the LAS test uses the same parallel plate configuration with the RCD as the TS test, it also inherits similar drawbacks from the TS test, such as the non - uniform distribution of shear stresses and edge instability flow [29]. This study attempts to characterize the fatigue performance of modified bitumen aged long term with hot additives using the above fatigue test methods with RCD equipment. Different indicators of binder fatigue performance from different methods will be compared.

\section{Objectives}

The objectives of this study are as follows:

1) Compare fatigue performance indicators of different fatigue testing methods.

2) To study the effect of the content of plastic granules and hot additives on the fatigue performance of binders.

\section{Experimental Design}

\subsection{Materials}

70/100 penetration bitumen (Nynas) was used as the base bitumen in this study. The base bitumen is graded PG $64-$ 22 according to the Superpave specification. The SARA fractions (saturated fatty acids, aromatics, resins, and asphaltenes) of the base bitumen are respectively $7 \%, 51 \%$, $22 \%$, and $20 \%$. Waste plastic pellets at room temperature have an irregular shape. The fine grain size of the plastic granules varies from 0 to $0.5 \mathrm{~mm}$. The physical properties, composition, and particle size of the plastic granule particles are shown in Table 1. Treatment agents mainly consist of antioxidants/antiozonants and curing additives (eg, sulfur, zinc oxide, stearic acid, accelerator, and oil, etc.). Two types of non - foaming hot additives, namely Wax Product W and Chemical Product C, were used in this study. Additive $\mathrm{W}$ is a synthetic hard wax free from sulfur and other impurities. The additive begins to crystallize at a temperature below 90 LC and forms a lattice structure. It is a liquid cocktail of chemicals, such as surfactants, polymers, etc.

\subsection{Preparation of binder samples}

The binders were prepared in the laboratory by mixing different percentages of plastic granules with the base bitumen. Four plastic granules (GP) contents were used, respectively $5 \%, 10 \%, 15 \%$, and $20 \%$ by mass of bitumen 70/100. GPs were labeled as GP - 5, GP - 10, GP - 15, and GP - 20, depending on the amount of GP added. GPs were gradually added to the base bitumen accompanied by manual stirring for 5 min to ensure good pre - distribution of GPs. The material was then mixed using a high shear mixer (Sil verson) with a square hole sieve. The mixing temperature was $180^{\circ} \mathrm{C}$ and the mixing time was 30 min with a shear rate of $6000 \mathrm{rpm}$. This mixing condition was determined 
based on the objective of optimizing the mechanical properties of GP [4]. During the mixing process, the mixer head was fully submerged in the hot bitumen to prevent oxidative aging.

To study the effect of hot additives on the fatigue properties of binders, two types of hot additives were added to base bitumen and GP - 20 at $160{ }^{\circ} \mathrm{C}$ and mixed manually for 10 min. The resulting binders were designated 70/100 - W, 70/100 - C, GP - $20-\mathrm{W}$, and GP - 20 - C. The dosages of additives $\mathrm{W}$ and $\mathrm{C}$ were $2.0 \%$ and $0.6 \%$ for the base bitumen and GP - 20, respectively, based on the dosage recommended by the manufacturers and preliminary tests [4]. The mixing procedure is shown in Fig.1. All fresh binder samples were first short - term aged and then subjected to the pressure aging test (VSP) in a pressurized environment $(2.1 \pm 0,1 \mathrm{MPa})$ at an elevated temperature of $100{ }^{\circ} \mathrm{C}$ for $20 \mathrm{~h}$. Different RCD tests were carried out on these samples of long - term aged binder to compare their fatigue performance.

Table: Basic properties and particle size distribution of plastic granulate

\begin{tabular}{|c|c|c|c|}
\hline Properties & & \multicolumn{2}{|l|}{ Description } \\
\hline Source & & Truck types & \\
\hline Preparation Method & & \multicolumn{2}{|l|}{ Ambient } \\
\hline Color & & \multicolumn{2}{|l|}{ Transparent } \\
\hline Morphology & & \multicolumn{2}{|l|}{ Porous } \\
\hline Density $\left(\mathrm{g} / \mathrm{cm}^{3}\right)$ & & $1.15 \pm 0.05$ & \\
\hline \multicolumn{2}{|c|}{ Temperature decomposition (LC) } & $\sim 200$ & \\
\hline Additive & Total plastic (natural and synthetic) & 55 & \\
\hline \multicolumn{4}{|l|}{ Composition } \\
\hline & Black carbon $(\%)$ & 25 & \\
\hline & Processing agent $(\%)$ & 20 & \\
\hline \multirow[t]{8}{*}{ Grading } & Sieve $(\mathrm{mm})$ & Passing (\%) & Retained (\%) \\
\hline & 0.710 & 100 & 0 \\
\hline & 0.500 & 90 & 10 \\
\hline & 0.355 & 61 & 29 \\
\hline & 0.180 & 19 & 43 \\
\hline & 0.125 & 7 & 15 \\
\hline & 0.063 & 1 & 8 \\
\hline & pan & - & 3 \\
\hline
\end{tabular}

\subsection{Dynamic shear rheometer test}

As described above, different binders are prepared to study the effects of hot additives and plastic granule content on the fatigue performance of the binders. The experimental procedure to characterize the fatigue performance is presented in Figure 1

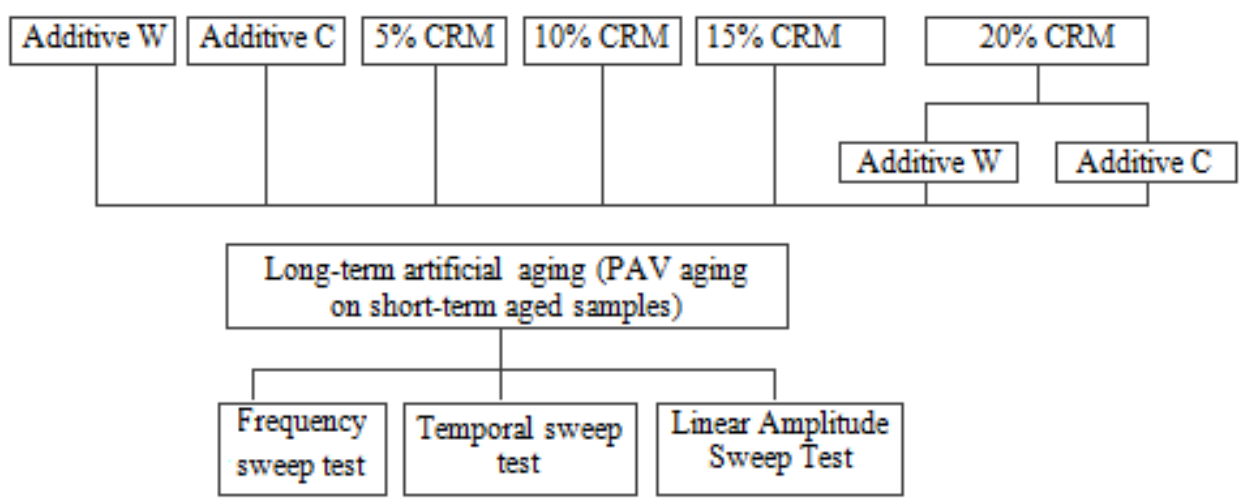

Figure 1: Experimental procedure to characterize the fatigue performance of binders

\subsubsection{Frequency sweep test}

The rheological parameters (mainly complex shear modulus and phase angle) of different binders were measured with an RCD (Anton Paar). Frequency sweep (FS) tests were performed using the $25 \mathrm{~mm}$ parallel plate geometry with a $1 \mathrm{~mm}$ deviation of 0.1 to $100 \mathrm{rads} / \mathrm{s}$ at temperatures of 10 , 20, 30, 40 and $50{ }^{\circ} \mathrm{C}$ according to the standard test procedure. All BF tests were conducted at a constant stress level of $0.1 \%$ to ensure the VEL response of the binders. The Superpave $\mathrm{G} * \sin \delta$ fatigue parameter and the $\mathrm{G}-\mathrm{R}$ parameter were extracted from the master curves established from the results of the LF tests. The rheological parameters in the intact state can also be obtained by these same tests.

\subsubsection{Time sweep and linear amplitude sweep test}

The TS (Time Sweep) and LAS (Linear Amplitude Sweep) tests were performed using the $8 \mathrm{~mm}$ parallel plate and $2 \mathrm{~mm}$ gap configuration. Two replicas were tested for each scenario. As mentioned in previous studies, adhesive failure and unstable flow can occur during the fatigue testing process at low or high temperatures [30]. To measure the true fatigue of the binder, the test temperature for the TS and LAS tests was chosen at $20^{\circ} \mathrm{C}$, which produced cohesive cracking with limited throughput. The test frequency was chosen at $10 \mathrm{~Hz}$. LV tests controlled by deformation were carried out at deformation levels of $2.5 \%$ and $5 \%$ which make it possible to obtain the rheological parameters in 
damaged condition. For the LAS test, the strain is increased linearly from 0.1 to $30 \%$ during 3100 load cycles for a total test time of $310 \mathrm{~s}$. Peak strain and shear stress, as well as complex shear modulus and phase angle are recorded every 1 s (10 load cycles).

\section{Method of Analysis}

\subsection{Linear viscoelasticity}

In this study, a modified Christensen - Anderson - Marseau (CAM) model (equations (1) and (2)) was adopted to construct the master curves based on the results of the BT tests [31].

$$
G^{\prime}=\frac{G^{s}}{\left(1+\left(\frac{f_{c}}{f_{g}}\right)^{k}\right)^{m / k}}
$$

where $\mathrm{Gg}$ is the $\mathrm{G}$ as the frequency approaches infinity, often called the complex modulus of glass; fc is the cutoff frequency; fr is the reduced frequency; and $\mathrm{k}, \mathrm{m}$ are the shape parameters, dimensionless.

$$
\delta=90 I-\frac{90 I-\delta m}{\left\{1+\left[\frac{\log \left(\frac{f d}{f r}\right)}{R d}\right]^{2}\right\}^{m d / 2}} \quad \text { eq2 }
$$

Where $\mathrm{dm}$ is the phase angle constant at fd, the value at the inflection point for binders; fd is the location parameter with a frequency dimension, at which $\mathrm{dm}$ occurred, $\mathrm{Rd}$ and $\mathrm{md}$ are the shape parameters.

$$
\log x_{T}(T)=\frac{-C 1\left(T-T_{R}\right)}{C_{2}+\left(T-T_{R}\right)}
$$

where $\mathrm{C}_{1}, \mathrm{C}_{2}$ are the constants determined empirically; $\mathrm{T}$ is the test temperature; TR is the reference temperature; $\mathrm{aT}$ is the shift factor.

The two transition points separating the three damage stages can be defined using the concept of cumulative dissipated energy ratio (DER) as shown in the equation. (4)

$$
D E R_{n}=\frac{\sum_{i}^{n} w i}{w_{n}}
$$

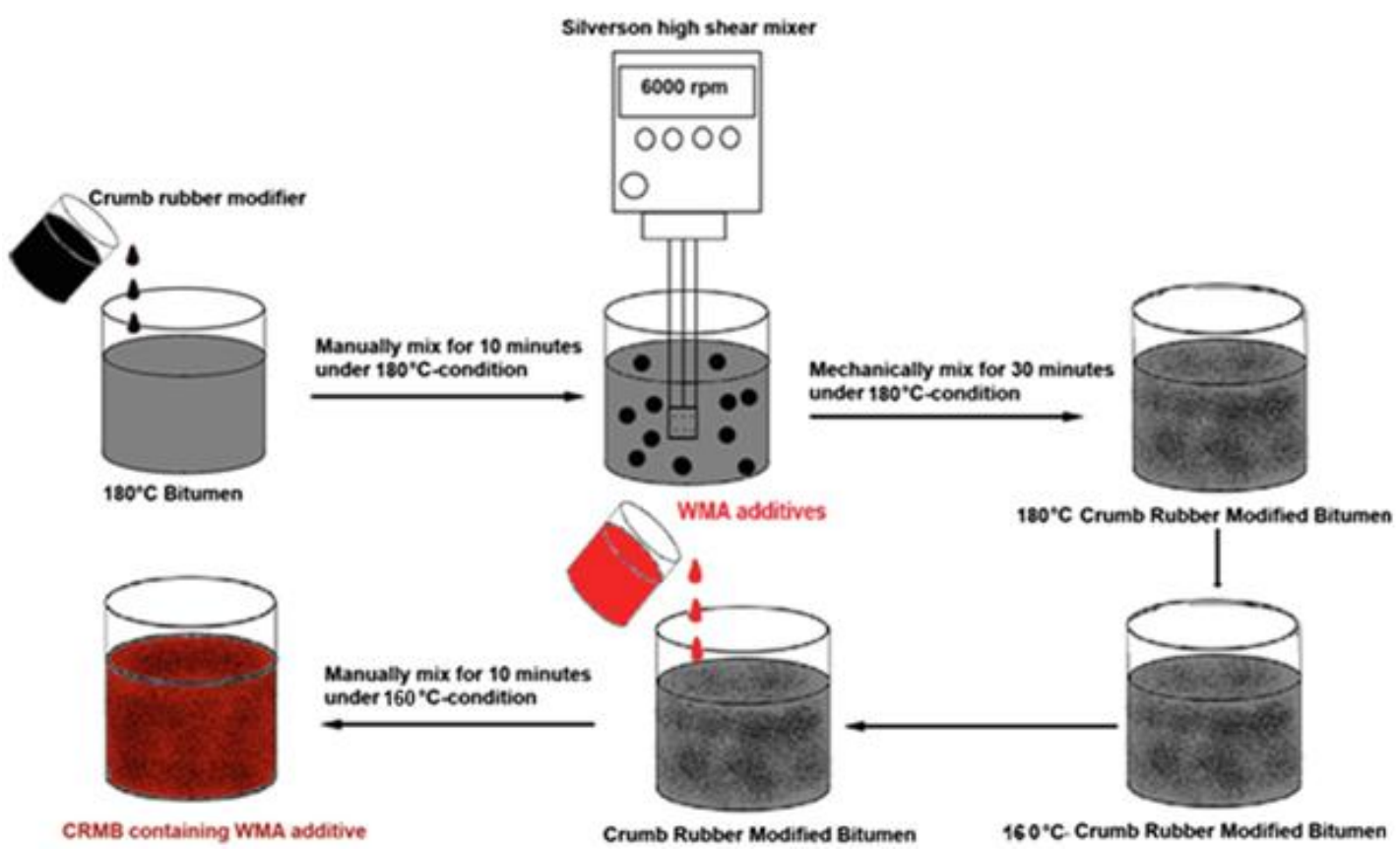

Figure 2: Samples preparation

4.2 Modeling based on the dissipated energy of the temporal sweep test

Figure 3 shows the three main stages of damage during the evolution of fatigue damage to binders [24]. In the first stage, the dissipated energy (DE) for each cycle is constant and no damage occurs. In the second step, the integrity of the material of the binders gradually deteriorates and a crack is initiated. At the stage of crack propagation, a rapid change in the response of the material is observed, and damage accumulates more aggressively until complete failure is achieved.

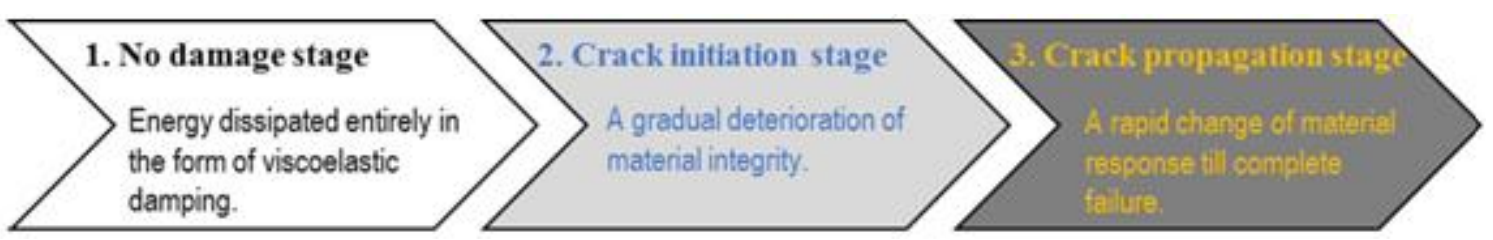

Figure 3: Evolution of damage linked to the fatigue of binders 
The two transition points separating the three damage stages can be defined using the concept of cumulative dissipated energy ratio (DER) as shown in the equation. (4), where Wi is the DE in a given cycle, which can be calculated using the stress and strain amplitudes in the nth cycle, $\mathrm{s} 0$; i and $\mathrm{c} 0$; i with

$$
W i=\pi \tau_{0} . i \gamma_{0}, i \sin (\delta i)
$$

$\mathrm{Wn}$ is the energy dissipated in the nth cycle.

The DER of each cycle is calculated using Eq. (4) and plot against the loading cycles to follow the evolution of fatigue. For a controlled LV strain test, the material deteriorates as the test progresses, reducing stress levels to keep the strain amplitude constant. Therefore, with the increase in the number of load cycles in a strain - controlled test, the DE in each cycle decreases while the DER steadily increases. Unlike the stress - controlled BT test, there is no clear point of failure for the stress - controlled test. A parameter called $\mathrm{Np} 20$ is proposed as a failure criterion. It is defined as the number of charge cycles at which the DER deviates from the equal line by $20 \%$. The parameter $\mathrm{Np}$ in the graph corresponds to the intersection of two asymptotes. The relationship between fatigue life and Initial D is described by a traditional power function (Eq. (6)) [24].

$$
N p 20=K_{2}\left(\frac{1}{w_{i}}\right)^{K_{\perp}} \text { eq } 6
$$

where $K_{1}$ and $K_{2}$ are the adjustment parameters related to the energy input of the binder and to the test temperature [25]. FIG.4 summarizes the evolution of the DER and the determination of $\mathrm{Np} 20$ in a controlled LV strain test. Conceptually, the fatigue life of the binder defined previously as Np20 is represented by the loading cycles necessary to undergo crack initiation without reaching crack propagation.

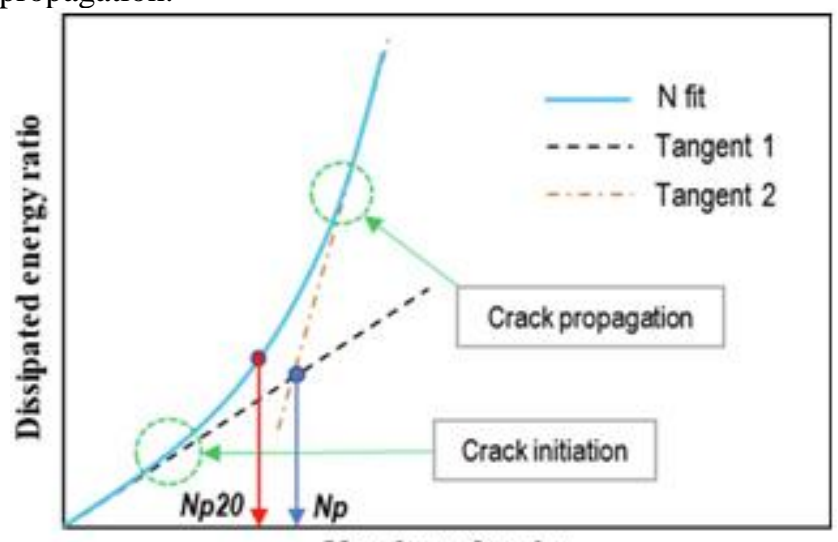

Number of cycles

Figure 4: DER variation for a stress - controlled temporal sweep test

\subsection{Simplified damages for the viscoelastic continuum (S - VECD) of the BAL test modeling}

LAS test results are interpreted using S - VECD theory. An integrated $S$ - VECD fatigue characterization framework consists of three material functions, namely the Lve property, the damage characteristic curve and the fatigue failure criterion [32]. To quantify the damage of the VECD modeling, an internal state variable $\mathrm{S}$ is introduced based on
Schachery's working potential theory [33] and can be derived from the law on the evolution of damage:

$$
\frac{d s}{d t}=\left(-\frac{\partial W^{R}}{\partial W}\right)^{X} \text { eq } 7
$$

where a is a material dependent constant that represents the rate of damage accumulation; $\mathrm{T}$ is the time; $\mathrm{WR}$ is the pseudo - distorted energy density. For this paper, the material parameter $\mathrm{A}$ is defined as $1 / \mathrm{m}+1$ for binders, where $\mathrm{M}$ is the slope of the master dynamic shear modulus curve in log space [34]. Pseudo - distorted energy is defined as follows:

$$
W_{R}=\frac{1}{2} D M R \cdot(S)\left(\gamma^{R}\right)^{2}
$$

Where DMR is the dynamic modulus ratio representing specimen - to - sample variability. The $\mathrm{C}$ is the pseudo rigidity to quantify the physical integrity as defined in the equation. (9).

$$
C(S)=\frac{\tau_{\mathrm{p}}}{\gamma^{R} \cdot D M R}
$$

where $\tau_{P}$ is the maximum stress in each cycle; $C_{R}$ is the amplitude pseudo - stress in each cycle which can be defined as in Eq. (10).

$$
\gamma \mathrm{R}=\frac{1}{\mathrm{GR}}(\gamma \mathrm{p} \cdot|\mathrm{G} *| \mathrm{LVE}) \quad \text { Eq } 10
$$

where GR is an arbitrary reference module; $g p$ is the amplitude of strain in each cycle.

$\left|\mathrm{G}^{*}\right|_{\text {LVE }}$ is the dynamic shear modulus LVE at temperature and fatigue test frequency. Bycombining the equations above, the damage at any time $t$ (characteristic curve of damage) can be derived in terms of integrity of the material as:

$$
\mathrm{S}(\mathrm{t})=\sum_{\mathrm{i}=1}^{\mathrm{N}} 1\left[\frac{\mathrm{DNR}}{2}(\gamma \mathrm{R}) 2(\mathrm{Ci}-1-\mathrm{Ci})\right] \frac{\mathrm{a}}{\mathrm{a}+1} \cdot(\mathrm{ti}-\mathrm{ti}-1) \frac{1}{1+a}
$$

where $\mathrm{N}$ is the load cycles and i refers to the cycle number. Since the relationship between $\mathrm{C}(\mathrm{S})$ and $\mathrm{S}$ is independent of the loading history, the $\mathrm{S}$ - VECD model is able to reverse calculate the fatigue life under all loading conditions of interest (for example, the level of deformation). To allow fatigue life predictions, a power law model is fitted to the damage characteristic curve (Eq. (12)) [28].

$$
C(S)=1-C_{1} \cdot S C 2
$$

$\mathrm{Eq} 12$

where $\mathrm{C}_{1}$ and $\mathrm{C}_{2}$ are model fit parameters. By combining the above equations, the relationship between fatigue life $\mathrm{Nf}$ and strain amplitude can be derived as [27]:

$$
N f=\frac{f \cdot 2^{X} \cdot S f^{1-} \alpha C 2^{+} \alpha}{\left(1-\alpha C_{2}+\alpha\right)\left(C_{1} C_{2}\right) \alpha\left(\gamma p \cdot|G *|_{L V E}\right)^{2 \alpha}}
$$

where Sf is the damage at the point of failure; $f$ is the loading frequency.

\section{Results and Discussion}

\subsection{Superpave Fatigue Parameter and G - R Parameter}

Complex shear moduli and phase angles of different binders at various temperatures and frequencies were obtained from frequency sweep tests. The values of the Superpave fatigue parameter and the $\mathrm{G}-\mathrm{R}$ parameter have been calculated for different binders and shown in Figs.5a and 5b, respectively. 
A lower value of $\mathrm{G} * \sin \delta$ is preferred to ensure better fatigue performance based on the Superpave specification.

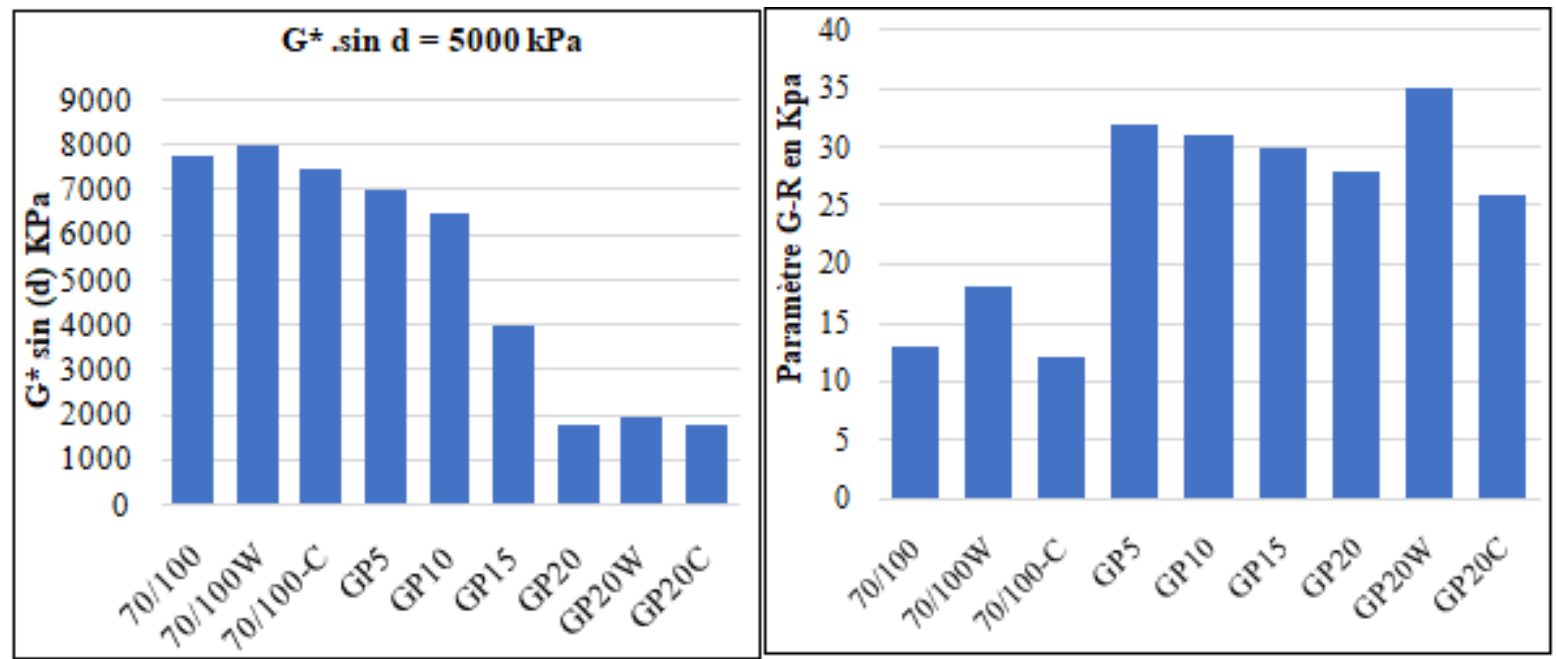

Figure 5a and 5b: Fatigue parameter $\mathrm{G} * \sin \delta / \mathrm{G}-\mathrm{R}$

It can be seen from Fig.5 that two types of warm additives have different effects on the fatigue parameter of both pure bitumen and modified bitumen. The wax - based additive is detrimental to the fatigue resistance of the binder while the chemical - based additive improves the fatigue resistance. It is evident that the modified binders have a higher fatigue resistance than pure bitumen. As the GP content increases, the $\mathrm{G} * \sin \delta$ decreases, indicating an increase in binder elasticity and fatigue resistance at intermediate temperatures. However, only the modified binders with a plastic granule (GP) content greater than $10 \%$ in this study meet the $\mathrm{G} * \sin$ $\delta$ requirement not to exceed $5000 \mathrm{kPa}$ at the PAV aging condition and at this temperature.

In terms of the $\mathrm{G}-\mathrm{R}$ parameter, similar to the results of the fatigue parameter, hot additives have opposite effects on the binder. The addition of wax - based additive makes the binder more brittle (higher stiffness / lower phase angle) while the chemical - based additive has a softening effect on the binder. However, modification with GP increases the value of the $G-R$ parameter of the binder, indicating more brittle behavior. As the GP content increases, the ductility of the binder slightly increases as reflected by the decrease in the $\mathrm{G}$ - R parameter. Considering a $\mathrm{G}-\mathrm{R}$ parameter value of $180 \mathrm{kPa}$ as the point of occurrence of damage, all binders tested are still intact.
Based on the above results, the Superpave fatigue parameter and the $\mathrm{G}-\mathrm{R}$ parameter provide inconsistent results on the fatigue performance of the binder. As mentioned earlier, both parameters are based on the point values of complex shear modulus and phase angle at a certain temperature and frequency under low strain load conditions. Therefore, changes in fatigue damage to a binder under a nonlinear range of large strain cannot be captured. TS and LAS tests were also carried out to study the fatigue performance of different binders.

\subsection{Time sweep test}

\subsubsection{Dissipated energy curve}

The TS test was designed to quantify the fatigue strength of the binder by monitoring the deterioration of the integrity of the material (usually the modulus) under repeated loads. Figure 6 shows a typical material response during the controlled stress TS test of 70/100 pure bitumen. The other binders also showed similar trends omitted here. It is evident that the complex modulus of the binder deteriorates faster at the high strain level of $5 \%$ than at $2.5 \%$, resulting in a shorter fatigue life. The simplest definition of fatigue failure for LV testing is the point corresponding to the $50 \%$ loss of stiffness. 


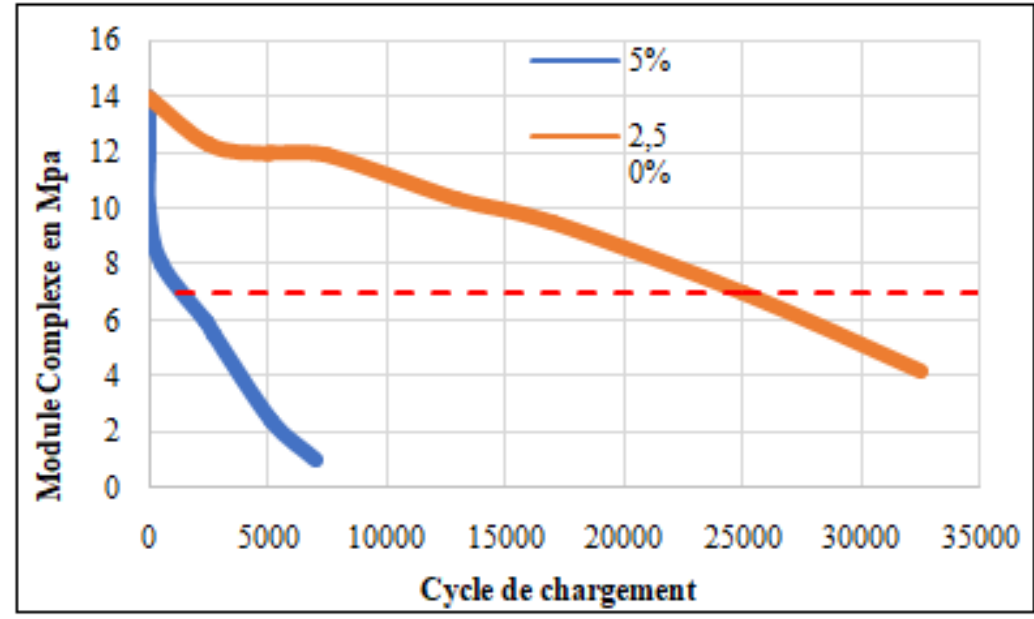

Figure 6: Evolution of the complex modulus of pure 70/100 bitumen in controlled strain BT fatigue tests

The red dotted line in Fig.7 represents the approximate 50\% reduction in the initial complex modulus of neat bitumen. The corresponding loading cycles of the two crossing points are the fatigue strength values at the two strain levels. However, this definition of fatigue failure has been criticized because it is arbitrary and lacks theoretical verification [23].
It has been proposed that parameters based on dissipated energy are more fundamentally related to fatigue failure. The dissipated energy approach was adopted to assess the fatigue property of binders and derive the fatigue law based on the BT results.
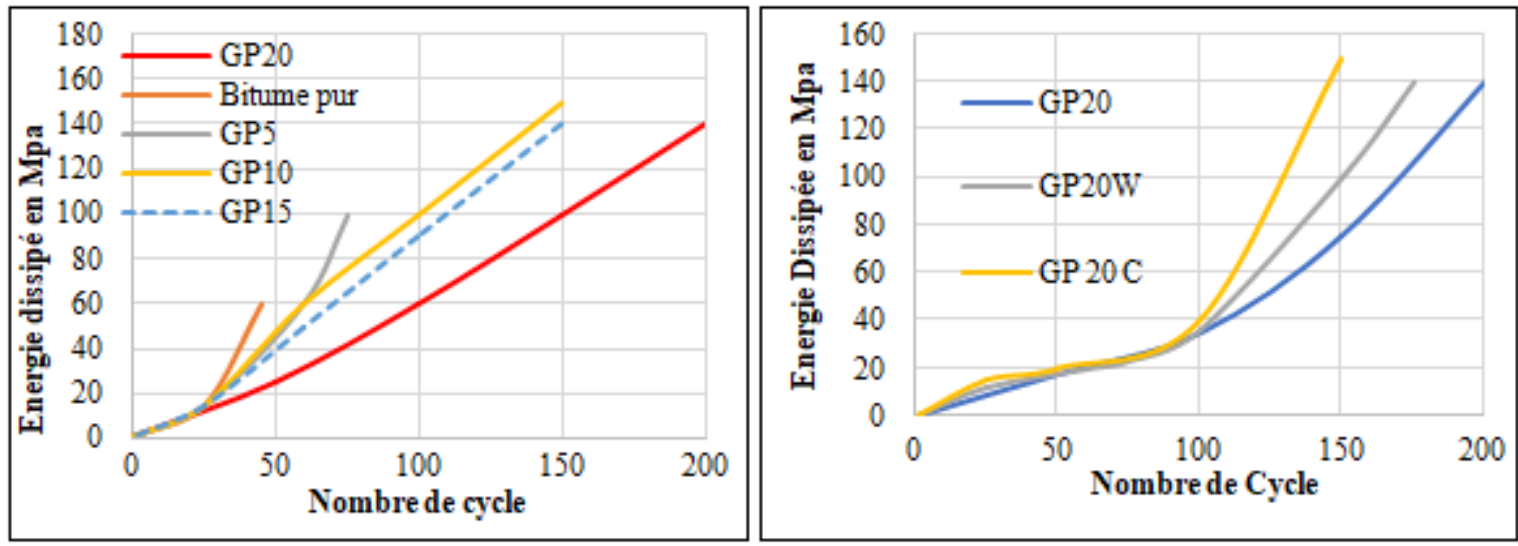

Figure 7a and 7b: Energy dissipated plots as a function of the number of load cycles from controlled stress LV tests at a stress level of 2.5\%: (a) bitumen with different GP contents; (b) GP20 modified bitumen with hot mixed additives

Fig.7 shows the DE curves of different binders with the progression of the loading cycles at the strain level of $2.5 \%$. At the initial stage, all binders show a linear increase in ED values with increasing loading cycles. This step is considered the damage - free step because the dissipated energy completely contributes to the viscoelastic damping without any damage. As the cyclic loading progresses, the trendline of $\mathrm{DE}$ as a function of the number of cycles deviates from the initial linear slope. The point of deviation is considered as the starting point of the crack. After more cumulative damage as the tests go on, the ED value will increase faster, and the crack propagation point will be reached. In terms of modification of the plastic granule, it can be seen from Figure 8a that GP binders show a wide range of results. Compared to neat bitumen, a delayed crack initiation can be observed for the GP binders of Figure $8 \mathrm{a}$. For pure bitumen and modified binders with relatively low GP content, the slope of the ED curves increases rapidly. The slope deviation from linearity was less pronounced for the GP - 15 and GP - 20 binders, indicating a significant improvement in fatigue resistance. Regarding hot additives, it seems that the wax - based additive causes an earlier crack initiation compared to neat bitumen while the addition of chemical based additive delays crack initiation as shown in figure $8 \mathrm{~b}$. However, the ED curves overlap at a later stage. Therefore, the exact fatigue life of each binder needs to be further determined by modeling the test results. Unlike the results for neat bitumen, the two types of warm additives improve the fatigue resistance of GP20 as shown in Figure $8 b$.

\subsubsection{Détermination de la durée de vie en fatigue}

To determine the fatigue life of the Np20 binder, the following model was used to fit the DER curve as a function of the number of load cycles [24].

$N=N c+b_{1}\left(R-R_{c}\right)+T\left(b_{2}-b_{1}\right) \ln \left\{1+e^{\left|\left(R-R_{T}\right) / T\right|}\right.$

Eq 14

where R represents ED; Nc and Rc are the constants of the model, representing respectively the number of charge cycles and the dissipated energy ratio; b1 and b2 are respectively the slopes of the lower asymptote and the upper asymptote of the curve of $\mathrm{N}$ as a function of $\mathrm{R}$; and $\mathrm{T}$ is the shape parameter. Microsoft Excel's solver function was 
adopted to calculate the values of model parameters using the least squares method.

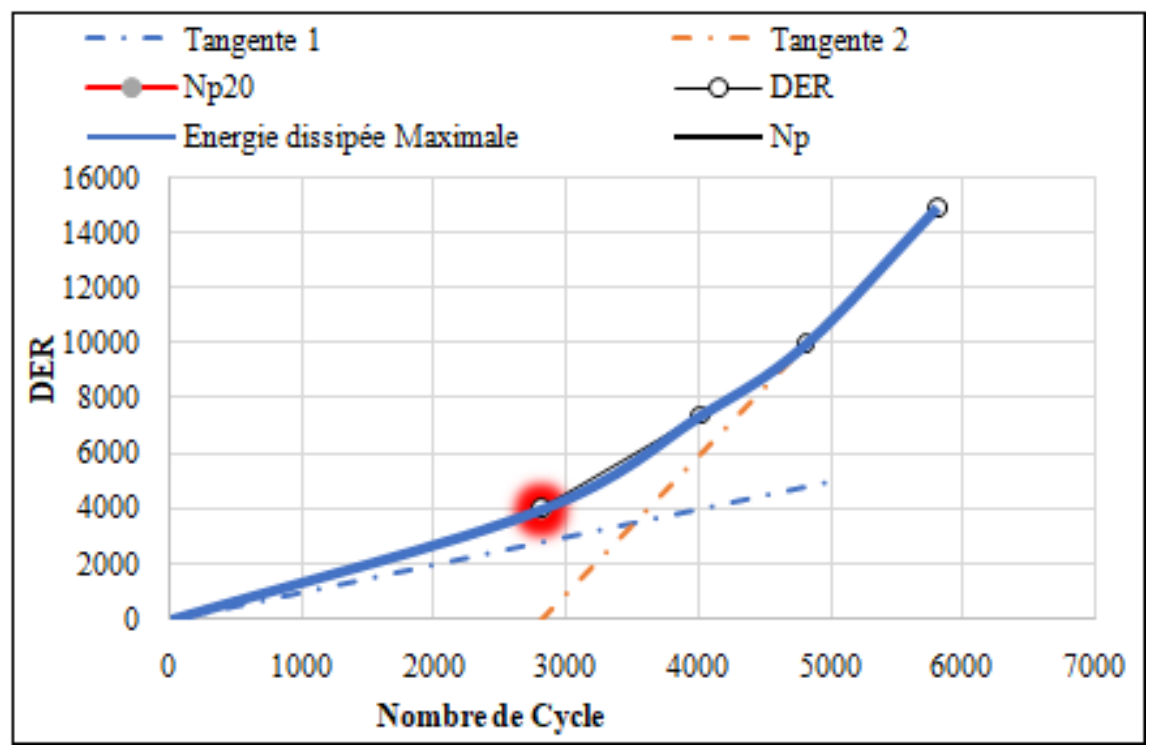

Figure 8: Modeling of the relationship between DER and the number of pure bitumen cycles at the 5\% strain level

Figure 8 shows an example of the calculation of the fatigue strength $\mathrm{Np} 20$ of neat bitumen. Similar procedures were applied to the other binders. For 70/100 pure bitumen, the fatigue life $\mathrm{Np} 20$ at a strain level of $5 \%$ is 2829 as summarized in Fig.9. To obtain the relation of fatigue in Eq. (6), at least two levels of energy input must be applied. This was achieved by performing the BT tests at two different stress levels, $2.5 \%$ and $5 \%$ respectively. The determined fatigue life Np20 and the fatigue model parameters $\mathrm{W}$ i, K1 and $\mathrm{K} 2$ of all the binders tested are summarized in Table 2.

Table 2: Fatigue life and model parameters from TS tests at controlled stress $(20 \mathrm{C}, 10 \mathrm{~Hz})$

\begin{tabular}{|c|c|c|c|c|c|}
\hline Bitumen & $\begin{array}{c}\text { Strain } \\
\text { level (\%) }\end{array}$ & $\mathrm{W}_{\mathrm{i}}(\mathrm{Pa})$ & $\mathrm{Np} 20$ & $\mathrm{~K}_{1}$ & $\mathrm{~K}_{2}$ \\
\hline \multirow{2}{*}{$70 / 100$} & 2.5 & $2.05 \mathrm{E}+04$ & $1.90 \mathrm{E}+04$ & \multirow{2}{*}{$4.57 \mathrm{E}+17$} & \multirow{2}{*}{$1.74 \mathrm{E}-03$} \\
\hline & 5.0 & $2.18 \mathrm{E}+04$ & $2.83 \mathrm{E}+03$ & & \\
\hline \multirow{2}{*}{$70 / 100 \mathrm{~W}$} & 2.5 & $2.29 \mathrm{E}+04$ & $1.26 \mathrm{E}+04$ & \multirow{2}{*}{$1.86 \mathrm{E}+07$} & \multirow{2}{*}{$3.18 \mathrm{E}-04$} \\
\hline & 5.0 & $2.88 \mathrm{E}+04$ & $1.96 \mathrm{E}+03$ & & \\
\hline \multirow{2}{*}{$70 / 100-C$} & 2.5 & $2.12 \mathrm{E}+04$ & $2.17 \mathrm{E}+04$ & \multirow{2}{*}{$-3.36 \mathrm{E}+12$} & \multirow{2}{*}{$9.35 \mathrm{E}-04$} \\
\hline & 5.0 & $2.34 \mathrm{E}+04$ & $3.07 \mathrm{E}+03$ & & \\
\hline \multirow{2}{*}{ GP5 } & 2.5 & $1.35 \mathrm{E}+04$ & $3.43 \mathrm{E}+04$ & \multirow{2}{*}{$-5.55 E+21$} & \multirow{2}{*}{$2.93 \mathrm{E}-03$} \\
\hline & 5.0 & $1.43 \mathrm{E}+04$ & $3.93 \mathrm{E}+03$ & & \\
\hline \multirow{2}{*}{ GP10 } & 2.5 & $1.16 \mathrm{E}+04$ & $5.18 \mathrm{E}+04$ & \multirow{2}{*}{$3.17 \mathrm{E}+10$} & \multirow{2}{*}{$1.15 \mathrm{E}-03$} \\
\hline & 5.0 & $1.36 \mathrm{E}+04$ & $5.35 \mathrm{E}+03$ & & \\
\hline \multirow{2}{*}{ GP15 } & 2.5 & $8.93 \mathrm{E}+03$ & $8.63 \mathrm{E}+04$ & \multirow{2}{*}{$-2.05 E+08$} & \multirow{2}{*}{$8.70 \mathrm{E}-04$} \\
\hline & 5.0 & $1.15 \mathrm{E}+04$ & $9.25 \mathrm{E}+03$ & & \\
\hline \multirow{2}{*}{ GP15 } & 2.5 & $6.54 \mathrm{E}+03$ & $1.15 \mathrm{E}+05$ & \multirow{2}{*}{$1.72 \mathrm{E}+08$} & \multirow{2}{*}{$1.12 \mathrm{E}-03$} \\
\hline & 5.0 & $8.51 \mathrm{E}+03$ & $1.27 \mathrm{E}+04$ & & \\
\hline \multirow{2}{*}{ GP20 } & 2.5 & $4.57 \mathrm{E}+03$ & $1.45 \mathrm{E}+05$ & \multirow{2}{*}{$7.17 \mathrm{E}+06$} & \multirow{2}{*}{$8.54 \mathrm{E}-04$} \\
\hline & 5.0 & $7.12 \mathrm{E}+03$ & $1.64 \mathrm{E}+04$ & & \\
\hline \multirow{2}{*}{ GP20C } & 2.5 & $3.26 \mathrm{E}+03$ & $1.81 \mathrm{E}+05$ & \multirow{2}{*}{$3.86 \mathrm{E}+06$} & \multirow{2}{*}{$9.38 \mathrm{E}-04$} \\
\hline & 5.0 & $5.63 \mathrm{E}+03$ & $1.96 \mathrm{E}+04$ & & \\
\hline
\end{tabular}

It can be seen in Table 2 that the initial energy input Wi has a negative correlation with the fatigue life Np20. Samples with a higher initial energy level have a shorter fatigue life. The measured fatigue life and associated model parameters of different binders summarized in Table 2 verified the effects of the modifiers on the fatigue performance of the base bitumen found from the DER evolution curves.
The modifying effect on the fatigue properties of the base bitumen depends on the particular characteristics of the modifier and the interaction between the modifier and the bitumen. The addition of a wax - based additive decreases the fatigue resistance (at controlled stress) of the base bitumen. The wax components form a crystalline structure at $20 \mathrm{C}$ in the bitumen matrix, which makes the binder more rigid, causing higher stresses at a certain level of strain and vulnerable to fatigue damage. The chemical based additive improves the fatigue resistance of the base bitumen due to the softening effect. The plastic granule modification significantly prolongs the fatigue strength of the base bitumen. The fatigue damage resistance improves with a higher plastic granule content in the controlled stress test. The plastic particles are swollen by absorbing the aromatic oils from the bitumen during the preparation stage. The interaction between plastic and bitumen results in a three dimensional polymer network, which prevents or delays the formation of microcracks under fatigue load. Unlike pure bitumen, the two additives contribute to improving the fatigue performance of the GP20 binder. One possible explanation could be that the additives promote interactions between bitumen and GP [35].

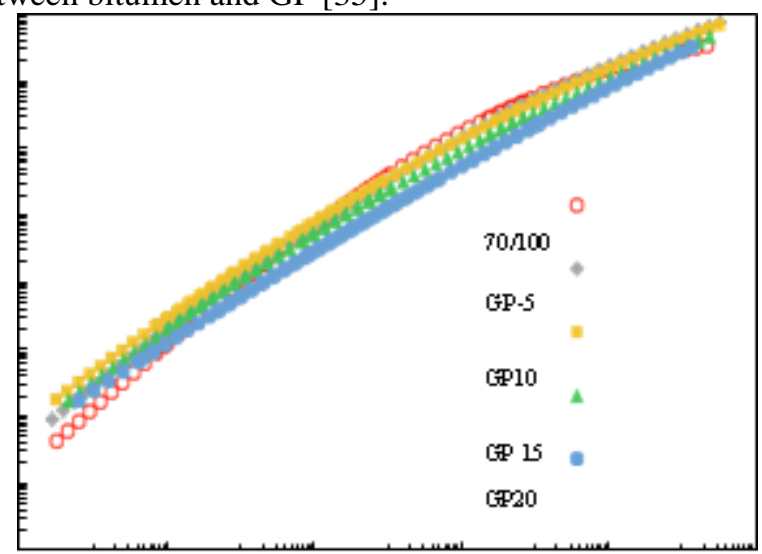

Figure 9: Complex master curves of shear modulus of binders at $20^{\circ} \mathrm{C}$ : (a) GP with different contents of plastic granules; (b) base bitumen with hot additives 


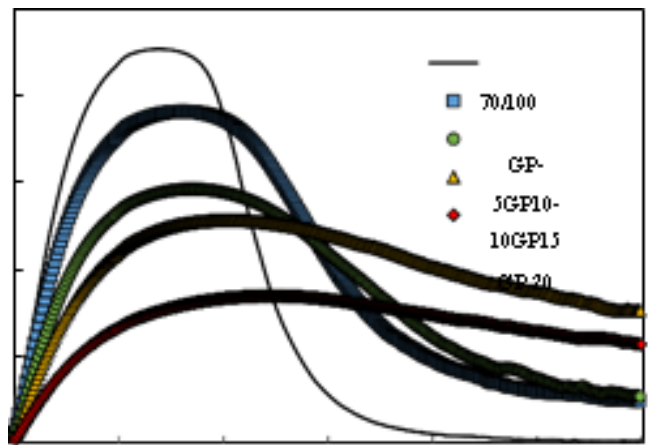

Figure 10: Apparent stress versus apparent strain of the LAS tests of the different types of binders

\subsection{BAL test}

\subsubsection{Complex modulus viscoelastic linear master curves} To obtain the material properties of the binder in the intact state, FS tests were carried out. Figure 10 shows the master curves of the complex shear modulus GjLVE of different binders at the reference temperature of $20 \mathrm{C}$. In general, modified binders have a higher complex shear modulus than pure bitumen in the low frequency range, while they have a lower complex shear modulus than pure bitumen in the high frequency range at the fatigue test temperature of $20 \mathrm{C}$. This may be explained by the nature of the plastic which behaves as a material. elastic with a higher modulus than bitumen at high temperature and lower than bitumen at lower temperatures. It can be seen from Figure 11 that GP20 has the lowest complex modulus at a frequency of about 62.8 $\mathrm{rad} / \mathrm{s}(10 \mathrm{~Hz})$. Regarding lukewarm additives, wax additive has constant stiffening effect on both pure bitumen and CRMB binder, while chemical based additive decreases the complex modulus of pure bitumen and binder CRMB. The reason has already been explained by the nature of the additives.

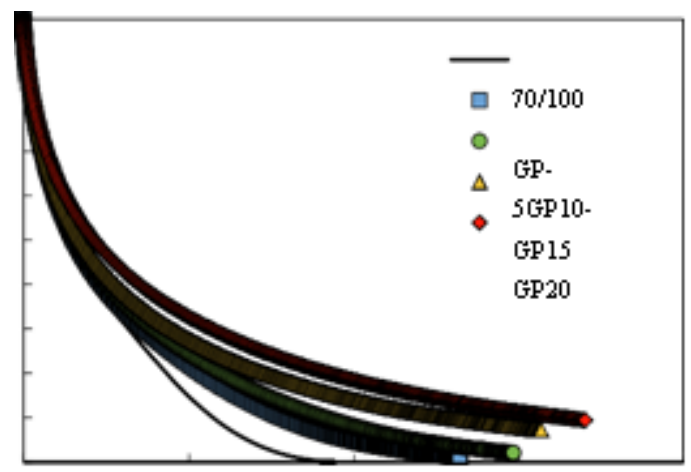

Figure 11: Characteristic curves of damage of the different binders

\subsubsection{Stress - strain response of different binders}

LAS tests were performed to assess the fatigue damage tolerance of the binders and were further analyzed using the $\mathrm{S}$ - VECD mockup. The apparent shear stress - strain curves of different binders from the results of the LAS tests are plotted in Figure 11. At the initial stage, the shear stress increases linearly with increasing loading strain. The further increase in strain amplitude slows the increase in shear stress. This is the time when the binders enter the nonlinear regions. Binders achieve maximum shear stress at different strain amplitudes. After the peak, the shear stress continuously decreases as the strain level increases further, indicating that significant damage has been induced in the material. It can be seen from Fig.11 that the modified binders with a higher GP content reach the stress peak at a greater amplitude of strain. This indicates that binders modified with higher GP contents exhibit higher damage resistance to shear loading. Adding warm mix additives to pure bitumen changes the level of strain at which peak stress occurs. When reaching the maximum shear stress, the corresponding strain for 70/100 is smaller than for 70/100 C, while being larger than for 70/100 - W. Both additives increase the value of the maximum shear stress and the corresponding strain for GP20.

$$
S f=\left(\frac{1-c_{f}}{c_{1}}\right)^{1^{\prime} C 2}
$$

where $\mathrm{Cf}$ is the value $\mathrm{C}$ at break, corresponding to the value $\mathrm{C}$ when the stress peak is reached in this case. Through the combination of equations. (15) and (13), the fatigue criterion which describes the relationship between the fatigue life $\mathrm{Nf}$ and the strain amplitude $\mathrm{Cp}$ can be derived as

$$
N_{f}=A\left(\gamma_{p}\right)^{B}
$$

where $\mathrm{A}$ is the model parameter defined in the equation. (17) with $\mathrm{B}=-2 \alpha$

$$
A=\frac{f \cdot 2^{\alpha} \cdot S_{f}^{k}}{k\left(C_{1} c_{2}\right)^{\alpha}\left(\left.|G *|\right|_{L V E}\right) 2^{\alpha}}
$$

$k=1-\alpha \mathrm{C}_{2}+\alpha ; \mathrm{f}$ is the charging frequency.

With the LVE property determined, the damage characteristic curve and the fatigue failure criterion, the fatigue life values and the model parameters from the LAS tests for different binders are determined (Table 3). Fatigue life at two strain levels of $2.5 \%$ and $5 \%$ has been predicted. It is observed that the modification of the GP significantly increases the fatigue life of the binder. Hot additives affect the fatigue strength of base bitumen differently compared to the modified binder. Both additives improve the fatigue performance of the modified binder. One possible explanation could be that hot additives improve the interaction between bitumen and GP, making the binder more resistant to fatigue damage. However, the wax - based additive considerably decreases the fatigue life of the base bitumen.

\subsection{Fatigue cracking in binders under dynamic shear loading}

The above results demonstrated that CRM and hot additives affect the fatigue strength of binders in different ways. This is due to the different microstructural compositions of the binders. Figure 13 shows the formation of fatigue cracks in the binder sample under dynamic shear load. Due to the non - uniform distribution of the shear stress in the circular binder sample under the applied torque (Fig.13a), circumferential hairline cracks start at the periphery of the sample and then propagate towards the center. Figure 13b shows a typical cracking morphology of the binder sample on the parallel plate with an annular crack zone and a circular non - crack zone, which is adapted from [13]. A small area in the crack area was selected as a representative area feature to analyze how the microstructures of different binders influence crack formation. For CRM modified 
binders, Figure 13c shows a swollen rubber particle embedded in the bitumen matrix with a multilayer structure due to the process of sequential diffusion of bitumen into the rubber [36]. In addition, previous studies have shown that swollen rubber is softer than bitumen at the intermediate temperature of $20 \mathrm{C}$ [37]. When the fatigue cracks initiated in the rigid bitumen phase start to propagate, they will meet the swollen rubber particle. Due to the similarity between the bitumen and the outer layer of rubber, microcracks will propagate in the rubber. However, due to the polymer network inside the rubber gel, crack propagation will be delayed. On a larger scale, the swollen rubber particles will form a three - dimensional network which can strengthen the binder to have greater resistance to cracking. This is the reason why CRMB binders have better fatigue performance than pure bitumen. For pure bitumen modified with a wax additive, the wax will crystallize at the test temperature of $20 \mathrm{C}$ and become very stiff. A stress concentration can occur at the interface between the bitumen and the wax. When the microcracks meet the wax structure, instead of propagating through the structure, they can only grow in other directions within the bitumen (Fig.13d), which accelerates the process of crack formation. Therefore, 70/100 - W binder has lower crack resistance than neat bitumen. As for the pure bitumen modified with a chemical based additive, it is believed that the softening effect is the main reason for improving the fatigue resistance. As with CRMB - 22 with wax additive, the increased interaction between rubber and bitumen due to the existence of wax could be a possible explanation for the improved fatigue performance [35].

\subsection{Comparison of binder fatigue parameters}

An important objective of this study was to compare the fatigue performance indicators of different test methods:

Table 3: Fatigue life and model parameters from LAS tests

\begin{tabular}{|c|c|c|c|c|}
\hline Binder & B parameter & A parameter & Nf@ 2, 5 & Nf@ 5 \\
\hline, $70 / 100$ & $1,42 \mathrm{E}+05$ & $-3,285$ & $7,77 \mathrm{E}+03$ & $7,97 \mathrm{E}+02$ \\
\hline $70 / 100-\mathrm{W}$ & $1,35 \mathrm{E}+05$ & $-3,555$ & $5,63 \mathrm{E}+03$ & $4,79 \mathrm{E}+02$ \\
\hline $70 / 100-$ C & $1,80 \mathrm{E}+05$ & $-3,24$ & $1,03 \mathrm{E}+04$ & $1,09 \mathrm{E}+03$ \\
\hline GP5 & $5,09 \mathrm{E}+05$ & $-3,485$ & $2,09 \mathrm{E}+04$ & $1,07 \mathrm{E}+03$ \\
\hline GP10 & $6,01 \mathrm{E}+05$ & $-3,665$ & $2,23 \mathrm{E}+04$ & $1,07 \mathrm{E}+03$ \\
\hline GP15 & $1,50 \mathrm{E}+06$ & 3,468 & $6,70 \mathrm{E}+04$ & $6,12 \mathrm{E}+03$ \\
\hline GP20 & $1,70 \mathrm{E}+06$ & 3,468 & $7,66 \mathrm{E}+04$ & $9,00 \mathrm{E}+03$ \\
\hline
\end{tabular}

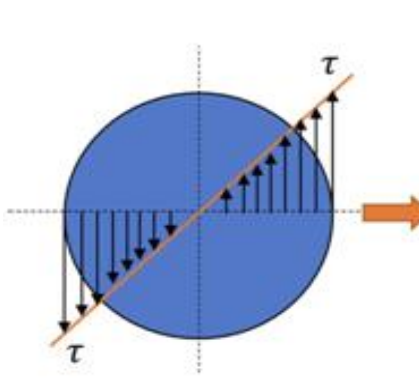

(a) Shear stress distribution

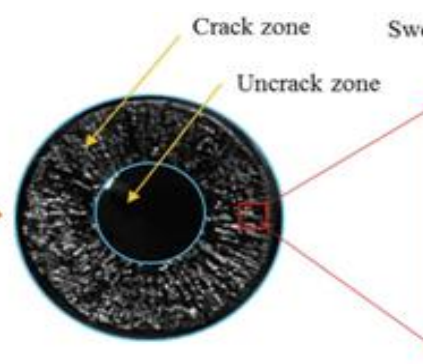

(b) Binder cracking surface

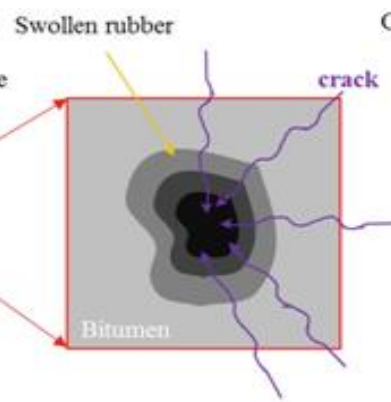

(c) CRMB

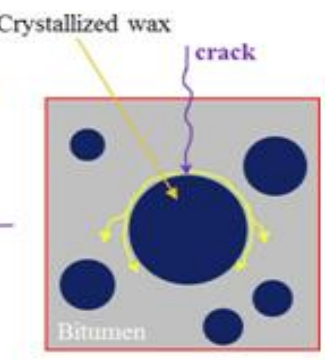

(d) Bitumen with waxbased additive

Figure 12: Fatigue life and model parameters from LAS tests.
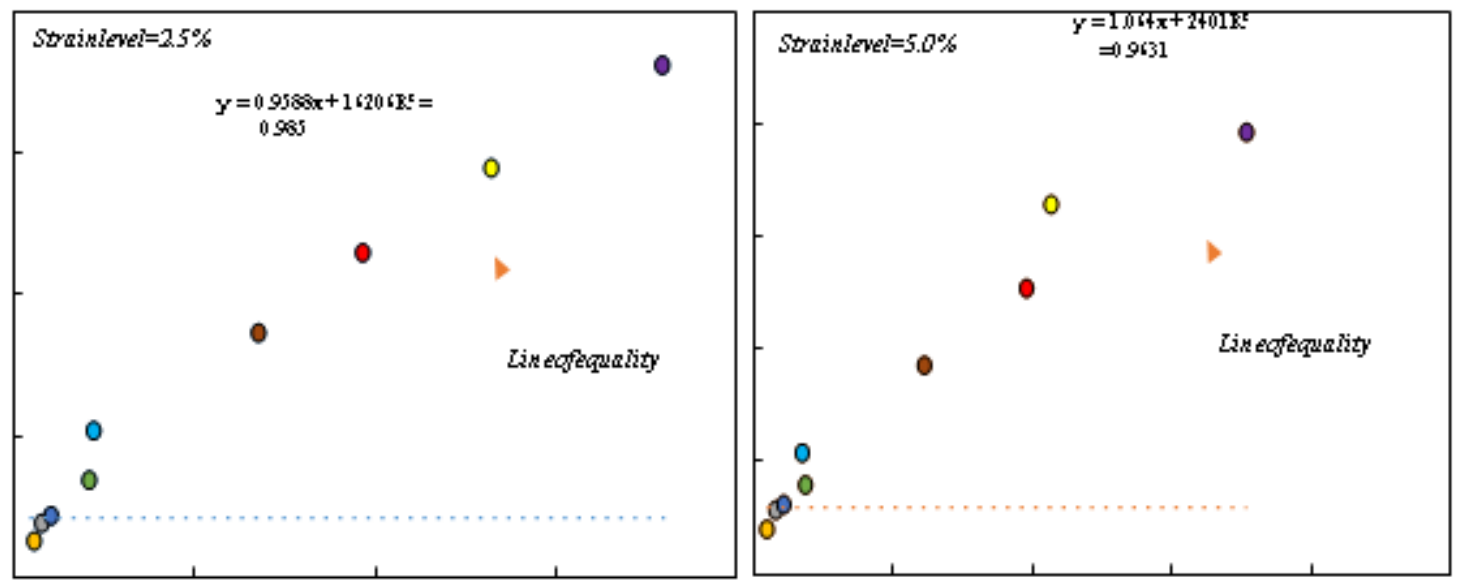

Figure 13: Comparison between fatigue life measured by TS and fatigue life predicted by LAS

Table 4: Classification of the fatigue performance of binders according to different parameters

\begin{tabular}{|c|c|c|c|c|c|c|c|c|}
\hline & Value $(\mathrm{kPa})$ & Classe & Value $(\mathrm{kPa})$ & Classe & Value & Class & Value & Class \\
\hline $70 / 100$ & 7777 & 8 & 12.76 & 2 & $1.90 \mathrm{E}+04$ & 8 & $7.77 \mathrm{E}+03$ & 8 \\
\hline $70 / 100-\mathrm{W}$ & 7913 & 9 & 18.73 & 3 & $1.26 \mathrm{E}+04$ & 9 & $5.63 \mathrm{E}+03$ & 9 \\
\hline $70 / 100-\mathrm{C}$ & 7219 & 7 & 10.87 & 1 & $2.17 \mathrm{E}+04$ & 7 & $1.03 \mathrm{E}+04$ & 7 \\
\hline GP5 & 6751 & 6 & 32.08 & 8 & $3.43 \mathrm{E}+04$ & 6 & $2.09 \mathrm{E}+04$ & 6 \\
\hline GP10 & 6356 & 5 & 31.23 & 7 & $5.18 \mathrm{E}+04$ & 5 & $2.22 \mathrm{E}+04$ & 5 \\
\hline GP15 & 4256 & 4 & 30.15 & 6 & $8.63 \mathrm{E}+04$ & 4 & $6.78 \mathrm{E}+04$ & 4 \\
\hline GP20 & 1901 & 1 & 28.94 & 5 & $1.15 \mathrm{E}+05$ & 3 & $9.66 \mathrm{E}+04$ & 3 \\
\hline
\end{tabular}


Table 4 summarizes the values of the Superpave fatigue parameter, G - R parameter, and fatigue life at the $2.5 \%$ stress level of the BT and LAS tests. The relative classification of the fatigue performance of the different binders is also given. A value of 1 to 9 represents best or worst for fatigue performance. It can be seen that the BT and LAS tests give exactly the same classification for the fatigue performance of the different binders. The Superpave fatigue parameter classifies the fatigue performance of the binders in a sequence similar to that of the BT and LAS tests, except for GP20 with hot additives. However, the classification of fatigue performance from the $\mathrm{G}-\mathrm{R}$ parameter is confusing and unreasonable. This is probably due to the fact that the $G$ - $\mathrm{R}$ parameter is a parameter not associated with the load and was determined at $15 \mathrm{C}$, which is different from the fatigue test temperature. As it has been proven that the BT test results of the binders correlate well with the fatigue performance of the mixture, they can be taken as a benchmark to characterize the fatigue performance of the binders. On this basis, the above results confirm that the LAS test can be used as a good substitute for the characterization of the fatigue performance of GP type binders at intermediate temperatures. The Superpave fatigue parameter fails to characterize fatigue performance when the binder is incorporated with GP and hot additives. The G - R parameter is not suitable for characterizing the fatigue strength of binders.

\section{Conclusions}

In this research, the fatigue performance of long - term aged plastic granule (GP) modified bitumen containing hot additives was investigated using different fatigue test methods. FS tests were performed to obtain the Superpave fatigue parameter and the $\mathrm{G}-\mathrm{R}$ parameter, as well as the linear viscoelastic properties of the binders which serve as parameters under undamaged conditions. The results of the BT tests were analyzed using the ED (Dissipated Energy) concept to determine the fatigue life of the binder. The $\mathrm{S}$ VECD theory was applied in the modeling of the results of the LAS (Linear Viscoelastic) test to predict the fatigue life of the binder. The following conclusions can be drawn based on the test results.

In terms of comparison between different fatigue characterization methods, the results of LAS tests correlate well with the results of BT (stress stress) tests. Both test methods give the same classification of fatigue strength for different binders. The LAS test can be used as an alternative to the BT test to characterize the fatigue performance of modified type binders at intermediate temperatures. The Superpave fatigue parameter works well, but in part "fails" to characterize the fatigue performance of the modified with hot additives. The $\mathrm{G}-\mathrm{R}$ parameter does not seem suitable for characterizing the fatigue strength of the binders.

Regarding the effects of modifying GP and hot additives, modified binders exhibit superior fatigue performance than pure bitumen. With increasing GP content, improving fatigue life is more important. The wax - based additive negatively influences the fatigue performance of neat bitumen while the chemical - based additive improves it.
Both additives are beneficial to GP20 in terms of increasing resistance to fatigue damage.

If the study used different fatigue failure criteria to analyze the results of the BT and LAS tests, a unified failure criterion can be applied to the analysis process of both tests in the future. The fatigue performance of the sealant and the mixture should also be evaluated to verify the results at the binder level.

\section{References}

[1] WBCSD, End - of - Life Tires: A framework for effective management systems, in: W. B. C. f. S. Development (Ed.) World Business Council for Sustainable Development, Conches - Geneva, Switzerland, 2010.

[2] K. Stevenson, B. Stallwood, A. G. Hart, Tire rubber recycling and bioremediation: A review, Biorem. J.12 (1) (2008) 1-11.

[3] D. LoPresti, Recycled tyre rubber modified bitumensforroad asphalt mixtures: A literature review, Constr. Build. Mater.49 (2013) 863-881.

[4] H. Wang, X. Liu, H. Zhang, P. Apostolidis, T. Scarpas, S. Erkens, Asphalt - rubber interaction and performance evaluation of rubberised asphalt binders containing non - foaming warm - mix additives, RoadMater. Pavem. Design (2018) 1-22.

[5] H. Wang, X. Liu, P. Apostolidis, T. Scarpas, Non Newtonian behaviors of crumb rubber - modified bituminous binders, Appl. Sci.8 (10) (2018) 1760.

[6] F. Farshidi, D. Jones, J. T. Harvey, Warm - Mix Asphalt Study: Evaluation of Rubberized Hot - and Warm - Mix Asphalt with Respect to Emissions, Research Report: UCPRC - RR - 2013 - 03, University of California Pavement Research Center, Davis, California, USA, 2013.

[7] G. L. Baumgardner, G. R. Reinke, Binder additives for warm mix asphalt technology, J. Assoc. Asphalt PavingTechnol.82 (2013) 685-709.

[8] T. Bennert, G. Reinke, W. Mogawer, K. Mooney, Assessment of workability and compact ability of warm - mix asphalt, Transport. Res. Record: J. Transp. Res. Board2180 (2010) 36-47.

[9] A. J. Hanz, A. Faheem, E. Mahmoud, H. U. Bahia, Measuring effects of warm - mix additives use of newly developed asphalt binder lubricity test for the dynamics hear rheometer, Transp. Res. Record 2180 (2180) (2010) 85-92.

[10] H. Wang, X. Liu, P. Apostolidis, T. Scarpas, Review of warm mix rubberized asphalt concrete: towards a sustainable paving technology, J. Cleaner Prod. 177 (2018) 302-314.

[11] R. Cao, Z. Leng, H. Yu, S. - C. Hsu, Comparative life cycle assessment of warm mixtechnologies in asphalt rubber pavements with uncertainty analysis, Resour. Conserv. Recycl.147 (2019) 137-144.

[12] H. Yu, Z. Leng, Z. Zhou, K. Shih, F. Xiao, Z. Gao, Optimization of preparation procedure of liquid warm mix additive modified asphalt rubber, J. CleanerProd.141 (2017) 336-345.

[13] Y. Zhang, Y. Gao, Predicting crack growth in visco elastic bitumen under a rotational shear fatigue load, 
RoadMater. Pavem. Des. (2019) 1-20.

[14] Y. Gao, Y. Zhang, Y. Yang, J. Zhang, F. Gu, Molecular dynamics investigation of interfacial adhesion between oxidised bitumen and mineral surfaces, Appl. Surf. Sci.479 (2019) 449-462.

[15] R. Hajj, A. Bhasin, The search for a measure of fatigue cracking in asphalt binders - a review of different approaches, Int. J. Pavement Eng.19 (3) (2017) 205219.

[16] D. A. Anderson, T. W. Kennedy, Development of SHRP binder specification, J. Assoc. AsphaltPavingTechnol.62 (1993) 481-507.

[17] H. U. Bahia, H. Zhai, K. Onnetti, S. Kose, Non - linear visco elastic and fatigue properties of asphalt binders, J. Assoc. AsphaltPavingTechnol.68 (1999) 1-34.

[18] H. U. Bahia, H. Zhai, M. Zeng, Y. Hu, P. Turner, Development of binder specification parameters based on characterization of damage behavior, J. Assoc. AsphaltPavingTechnol.70 (2001) 442-470.

[19] G. M. Rowe, G. King, M. Anderson, The influence of binder rheology on the cracking of asphalt mixes in airport and highway projects, J. Test. Eval.42 (5) (2014) 20130245.

[20] R. M. Anderson, G. N. King, D. I. Hanson, P. B. Blankenship, Evaluation of the relationship between asphalt binder properties and non - load related cracking,

[21] J. Assoc. AsphaltPavingTechnol.80 (2011) . H. U. Bahia, D. I. Hanson, M. Zeng, H. Zhai, M. A. Khatri, R. M. Anderson, Characterization of Modified Asphalt Binders in Super pave Mix Design, NCHRPReport459, Transportation Research Board, Washington D. C, 2001.

[22] D. A. Anderson, Y. M. LeHir, M. O. Marasteanu, J. P. Planche, D. Martin, G. Gauthier, Evaluation of fatigue criteria for asphalt binders, Transp. Res. Record1766 (2001) 48-56.

[23] C. Wang, H. Zhang, C. Castorena, J. Zhang, Y. R. Kim, Identifying fatigue failure in a sphalt binder time sweep tests, Constr. Build. Mater.121 (2016) 535-546.

[24] K. S. Bonnetti, K. Nam, H. U. Bahia, Measuring and defining fatigue behavior of asphalt binders, TranspResRecord2002 (1810) 33-43.

[25] R. Delgadillo, H. Bahia, Rational fatigue limits for asphalt binders derived from pavement analysis, J. Assoc. AsphaltPavingTechnol.78 (2005) 97-138.

[26] W. Cao, C. Wang, A new comprehensive analysis framework for fatigue characterization of asphalt binder using the Linear Amplitude Sweeptest, Constr. Build. Mater.171 (2018) 1-12.

[27] C. Wang, C. Castorena, J. Zhang, Y. RichardKim, Unified failure criterion for asphalt binder under cyclic fatigue loading, RoadMater. Pavem. Design16 (sup2) (2015) 125-148.

[28] C. Hintz, R. Velasquez, C. Johnson, H. Bahia, Modification and validation of linear amplitude sweep test for binder fatigue specification, Transp. Res. Record: J. Transp. Res. Board2207 (2011) 99-106.

[29] C. Hintz, H. Bahia, Understanding mechanisms leading to asphalt binder fatigue in the dynamic shear rheometer, Road Mater. Pavem. Design 14 (sup2) (2013) 231-251.

[30] F. Safaei, C. Castorena, Temperature effects of linear amplitude sweep testing and analysis, Transp. Res. Record: J. Transp. ResBoard2574 (2016) 92-100.

[31] H. Wang, X. Liu, P. Apostolidis, T. Scarpas, Rheological behavior and its chemical interpretation of crumb rubber modified asphalt containing warm - mix additives, Transp. Res. Record: J. Transp. Res. Board 2672 (28) (2018) 337-348.

[32] B. S. Underwood, C. Baek, Y. R. Kim, Simplified viscoelastic continuum damage model as platform for asphalt concrete fatigue analysis, Transp. Res. Record2296 (2012) 36-45.

[33] R. Schapery, Analysis of damage growth in particulate composites using a work potential, Compos. Eng.1 (3) (1991) 167-182.

[34] F. Safaei, J. - S. Lee, L. A. H. D. Nascimento, C. Hintz, Y. R. Kim, Implications of warm - mix asphalt on long - term oxidative ageing and fatigue performance of asphalt binders and mixtures, RoadMater. Pavem. Des.15 (sup1) (2014) 45-61.

[35] H. Yu, Z. Leng, Z. Gao, Thermal analysis on the component interaction of asphalt binders modified with crumb rubber and warm mix additives, Constr. Build. Mater.125 (2016) 168-174.

[36] H. Wang, X. Liu, P. Apostolidis, S. Erkens, T. Scarpas, Numerical investigation of rubber swelling in bitumen, Constr. Build. Mater.214 (2019) 506-515.

[37] H. Wang, X. Liu, P. Apostolidis, S. Erkens, A. Skarpas, Experimental investigation of rubber swelling in bitumen, Transp. Res. Record: J. Transp. Res. Board (2020). Submitted. 